\title{
Direct $\mathrm{Csp}^{2}-\mathrm{Csp} \mathbf{p}^{3}$ cross-coupling of diarylzinc reagents with benzylic, $1^{\circ}, 2^{\circ}$ and $3^{\circ}$ alkyl halides ${ }^{\star \star}$
}

\author{
Jay J. Dunsford, Ewan R. Clark and Michael J. Ingleson*
}

\begin{abstract}
In this article, we report on the direct Csp ${ }^{2}-\mathrm{Csp}^{3}$ crosscoupling of diarylzinc reagents with benzylic, $1^{\circ}, 2^{\circ}$ and $3^{\circ}$ alkyl halides. Under etherate-free conditions, cross-coupling proceeds rapidly at ambient temperature with benzylic, $2^{\circ}$ and $3^{\circ}$ alkyl halide substrates without addition of an external catalyst. The Csp ${ }^{2}-\mathrm{Csp}^{3}$ cross-coupling has excellent functional group tolerance and products are isolated in high yields, generally without the requirement for purification by chromatography. This process represents an expedient, operationally simple method for the construction of new $C s p^{2}-C s p^{3}$ bonds.
\end{abstract}

The efficient construction of new carbon-carbon bonds is of the utmost importance to contemporary molecular synthesis. ${ }^{[1]}$ In particular, the generation of new $C s p^{2}-C s p^{3}$ bonds represents a significant enabler for the preparation of complex molecules prevalent in both pharmaceutical agents and natural products..$^{[2-3]}$ Current state-of-the-art methods for the generation of $\mathrm{Csp}^{2}-\mathrm{Csp}{ }^{3}$ bonds typically employ alkyl electrophiles, organometallic nucleophiles (based upon organotin, organoboron, organozinc or organomagnesium reagents) and palladium ${ }^{[4-8]}$ or nickel ${ }^{[9-12]}$ based (pre)catalysts. Complementary methodologies have also emerged that employ organolithium reagents in palladium catalyzed ${ }^{[13]}$ or transition metal-free ${ }^{[14]}$ approaches to $\mathrm{Csp}^{2}-\mathrm{Csp} p^{3}$ bond formation. Despite these notable advances, challenges in cross-coupling chemistry still remain including the development of a single system applicable to the cross-coupling of benzylic, $1^{\circ}, 2^{\circ}$ and $3^{\circ}$ alkyl halides with electron rich, electron deficient and sterically hindered aryl nucleophiles.

In recent years there has been a conscious move towards the development of new cross-coupling methodologies that employ cheaper and more environmentally benign (pre)catalysts. Iron catalysts have achieved impressive advances in this area, particularly in the cross-coupling of alkyl electrophiles with organomagnesium reagents and, to a lesser extent organozinc reagents. ${ }^{[15-20]}$ Zinc systems able to generate $\mathrm{Csp} p^{2}-\mathrm{Csp} p^{3}$ bonds from alkyl halides and aryl nucleophiles would also be particularly attractive due to the low cost, low toxicity and environmentally benign nature of zinc. ${ }^{[21]}$ Whilst the utility of organozinc reagents in certain catalytic and stoichiometric carbon-carbon bond forming reactions is well established (e.g., as catalysts for the Aldol reaction $^{[21]}$ and in the direct addition of $R_{2} Z n$ to carbonyls, ${ }^{[22]}$ respectively), zinc systems that can activate alkyl halide electrophiles for subsequent cross-coupling are extremely limited. Recent reports have shown that zinc compounds are indeed viable for the cross-coupling of alkyl halides with activated diboron reagents in the absence of additional catalysts in a radical mediated

[*] Dr J. J. Dunsford, Dr E. R. Clark, Dr M. J. Ingleson

School of Chemistry, University of Manchester

Oxford Road, Manchester M13 9PL (UK)

E-mail: Michael.Ingleson@manchester.ac.uk

${ }^{\left.{ }^{*}\right]}$ The authors gratefully acknowledge the Royal Society (M.J.I. for the award of a University Research Fellowship) the European Research Council (J.J.D. Grant number 305868) and the Leverhulme trust (E.R.C.). We also acknowledge the Engineering and Physical Sciences Research Council (grant number EP/K039547/1) for financial support and Dr. Alessandro Del Grosso for helpful discussions relating to this project.

Supporting information for this article is given via a link at the end of the document. process. ${ }^{[23]}$ However, the direct, or zinc catalysed, coupling of aryl zinc nucleophiles with alkyl halides to form new $\mathrm{Csp} p^{2}-\mathrm{Csp}^{3}$ bonds is to the best of our knowledge unknown beyond examples using allyl and propargyl halides. ${ }^{[24-25]}$ Herein, we report on the solvent dependent direct $\mathrm{Csp}^{2}-\mathrm{Csp} p^{3}$ cross-coupling of diarylzinc reagents with a wide range of benzylic, $1^{\circ}, 2^{\circ}$ and $3^{\circ}$ alkyl halides in an operationally simple manner which allows expedient access to a diverse range of carbon based structural motifs.

During ongoing investigations into iron catalyzed $\mathrm{Csp}^{2}-\mathrm{Csp}{ }^{3}$ cross-coupling transformations and in particular the hydrocarbyl transmetallation step employing arylboronate nucleophiles ${ }^{[26]}$ we became interested in the roles of additives such as diarylzinc reagents in these transformations. ${ }^{[27-28]}$ Control experiments examining the influence of diarylzinc additives included the stoichiometric addition of diphenylzinc, $\mathbf{1}$, to a prototypical electrophile, 3-methoxybenzyl bromide, 2 , in benzene- $d_{6}$ without the transition metal catalyst. This produced an unexpected outcome in that within 5 minutes at ambient temperature, a colourless precipitate had separated from solution (presumably $\mathrm{PhZnBr}$ ) and analysis of the soluble components by ${ }^{1} \mathrm{H}$ and ${ }^{13} \mathrm{C}\left\{{ }^{1} \mathrm{H}\right\}$ NMR spectroscopy revealed the complete consumption of $\mathbf{2}$ and formation of a single new species, consistent with the $\mathrm{Csp} p^{2}-\mathrm{Csp} p^{3}$ crosscoupled product, 3a (Table 1, entry 1). The assignment of perprotio3a formed from 1 and 2 was also confirmed by GC-MS, ruling out any Friedel-Crafts benzylation of the benzene- $d_{6}$ solvent. ${ }^{[29]}$ This was an extremely surprising outcome considering previous investigations concerning the stoichiometric arylation of 3-methoxybenzyl bromide with 1 in dioxane afforded essentially no cross-coupled product (3\%) after $16 \mathrm{~h}$ at $60^{\circ} \mathrm{C} .^{[30]}$

Table 1. Direct arylation of $\mathbf{2}$ with $\mathbf{1}$ in the presence / absence of additives ${ }^{[a]}$

\begin{tabular}{llllllll}
\hline & & & & \\
\hline
\end{tabular}

[a] Standard reaction conditions: diphenylzinc $(99 \%)(22.0 \mathrm{mg}, 0.1 \mathrm{mmol}) ; 3-$ methoxybenzyl bromide ( $14.0 \mu \mathrm{L}, 0.1 \mathrm{mmol})$; solvent $(0.8 \mathrm{~mL}) ;+$ - additive (1 or 10 equiv.).

The influence of solvent, particularly an excess of coordinating ethereal solvents was subsequently investigated as the likely cause of the disparity between outcomes. The reaction between $\mathbf{1}$ and $\mathbf{2}$ performed in benzene- $d_{6}$ with the addition of THF (10 equiv.), resulted in the drastic suppression of reactivity (entry 2). Even after $20 \mathrm{~h}$, only $19 \%$ of the cross-coupled product, 3a, was observed along with $2(78 \%)$ and 1,2-bis(3-methoxyphenyl)ethane 4 (3\%). Increasing the reaction temperature to $60^{\circ} \mathrm{C}$ did afford an increase in both cross-coupled and homo-coupled products 3a and $\mathbf{4}$ (65\% and 
$24 \%$, respectively after $20 \mathrm{~h}$, entry 3 ) but the reaction is still extremely slow relative to the THF-free analogue. These observations suggest a strong solvent dependence, reinforced through reactivity suppression on the addition of either diethyl ether (10 equiv., entry 4) or tert-butylmethyl ether (MTBE) (10 equiv., entry 5), albeit to a lesser extent. Remarkably, even the addition of stoichiometric quantities of THF was sufficient to significantly retard the rate of reactivity (entry 6 ). Conducting the reaction in toluene- $d_{8}$ led to the desired cross-coupled product, $3 \mathbf{a}(69 \%)$ along with two isomers derived from Friedel-Crafts benzylation of the toluene- $d_{8}$ solvent $(31 \%){ }^{[31]}$ In contrast, using the less nucleophilic aromatic solvent, chlorobenzene produced only $\mathbf{3 a}$ with comparable reactivity to the reaction performed in benzene- $d_{6}$ ( $c f$. entries 1 and 7 ). It is also noteworthy that reducing the diphenylzinc concentration to 0.5 equiv. led to the generation of $\mathbf{3 a}$ in $89 \%$ yield in benzene- $d_{6}$ within 10 minutes, thus both aromatic equivalents on 1 can be utilized for cross-coupling. ${ }^{[31]}$ Furthermore, the employment of reagent grade 'wet' benzene- $d_{6}$ led to no decrease in observed overall yield.

Considering that the above reactivity proceeds in the absence of any added catalyst, we were mindful of the fact that trace amounts of highly active late-transition metal impurities can result in apparent 'catalyst-free' cross-coupling protocols. ${ }^{[32]}$ To probe the influence of trace impurities, diphenylzinc obtained from multiple sources and of varying purity was used and gave comparable rapid crosscoupling. ${ }^{[1]}$ Further analysis of the starting materials for trace metal impurities by inductively coupled plasma-mass spectrometry (ICPMS) revealed exceedingly low concentrations $(<0.01 \mathrm{ppm})$ of common non-innocent trace impurities. ${ }^{[31]}$ These results gave us confidence that trace metal impurities were not accountable for the observed reactivity, nevertheless, we still examined this possibility further through the addition of palladium, nickel, copper and iron based additives to a number of model systems under the standard conditions. All these transition metal additives could be excluded as catalysts through observed relative rates and / or product distribution relative to the additive-free protocol. ${ }^{\left[{ }^{[1]}\right.}$ The observed reactivity is thus attributed to an uncatalyzed or zinc catalyzed process, in line with recent reports utilizing zinc catalysis for the borylation of alkyl halides. ${ }^{[23]}$

Satisfied that the reactivity observed in the model reaction (Table 1 , entry 1) was not impurity driven, the substrate scope applicable to this transformation with respect to the electrophile was evaluated (Figure 1). These reactions were all performed in benzene- $d_{6}$ to facilitate rapid analysis by in-situ NMR spectroscopy, obviously the use of less toxic solvents is highly desirable and we re-emphasise that chlorobenzene is also a viable solvent for this process. The heterocoupling of a range of benzylic halides (halide $=\mathrm{Br}$ or $\mathrm{Cl}$ ) with diphenylzinc, $\mathbf{1}$, in benzene- $d_{6}$ led to diarylmethanes $\mathbf{3 a - 3 i}$, incorporating; halide $(\mathrm{Cl}, \mathrm{Br}$ or I); ether; nitro; vinyl; and trifluoromethyl substituents in good to excellent isolated yields (70 $99 \%)$. Remarkably, in the majority of cases short reaction times were sufficient (<10 minutes) for complete conversion at ambient temperature, with reaction completion indicated by precipitation of $\mathrm{PhZnX}(\mathrm{X}=\mathrm{Br}$ or $\mathrm{Cl})$. After this time, simple filtration of the crude reaction mixtures typically afforded pure diarylmethanes (as judged by GC-MS and NMR spectroscopy) without the necessity for chromatography or any further purification. It was also possible to scale up the synthesis of $3 a$ to $5.0 \mathrm{mmol}$ without any significant erosion of isolated yield (93\%). We note that in contrast to the addition of even stoichiometric aliphatic ethers no significant reactivity suppression is observed with arylethers as indicated by comparable rates for formation of $\mathbf{3} \mathbf{a}$ and $\mathbf{3} \mathbf{b}$.

A range of secondary alkyl halide substrates (halide $=\mathrm{Br}$ or $\mathrm{Cl}$ ) could also be effectively coupled with $\mathbf{1}$ at ambient temperature to generate compounds 5a-5i incorporating ester; vinyl; and tert butyloxycarbonyl protected amine functionalities (isolated yields 86 $97 \%$ ). Triarylmethane $\mathbf{5 j}$ was also accessed in excellent isolated yield $(96 \%,<10$ minutes at ambient temperature) demonstrating the utility of this method for the generation of triarylmethanes which are ubiquitous motifs in medicinal / biological chemistry. ${ }^{[33]}$

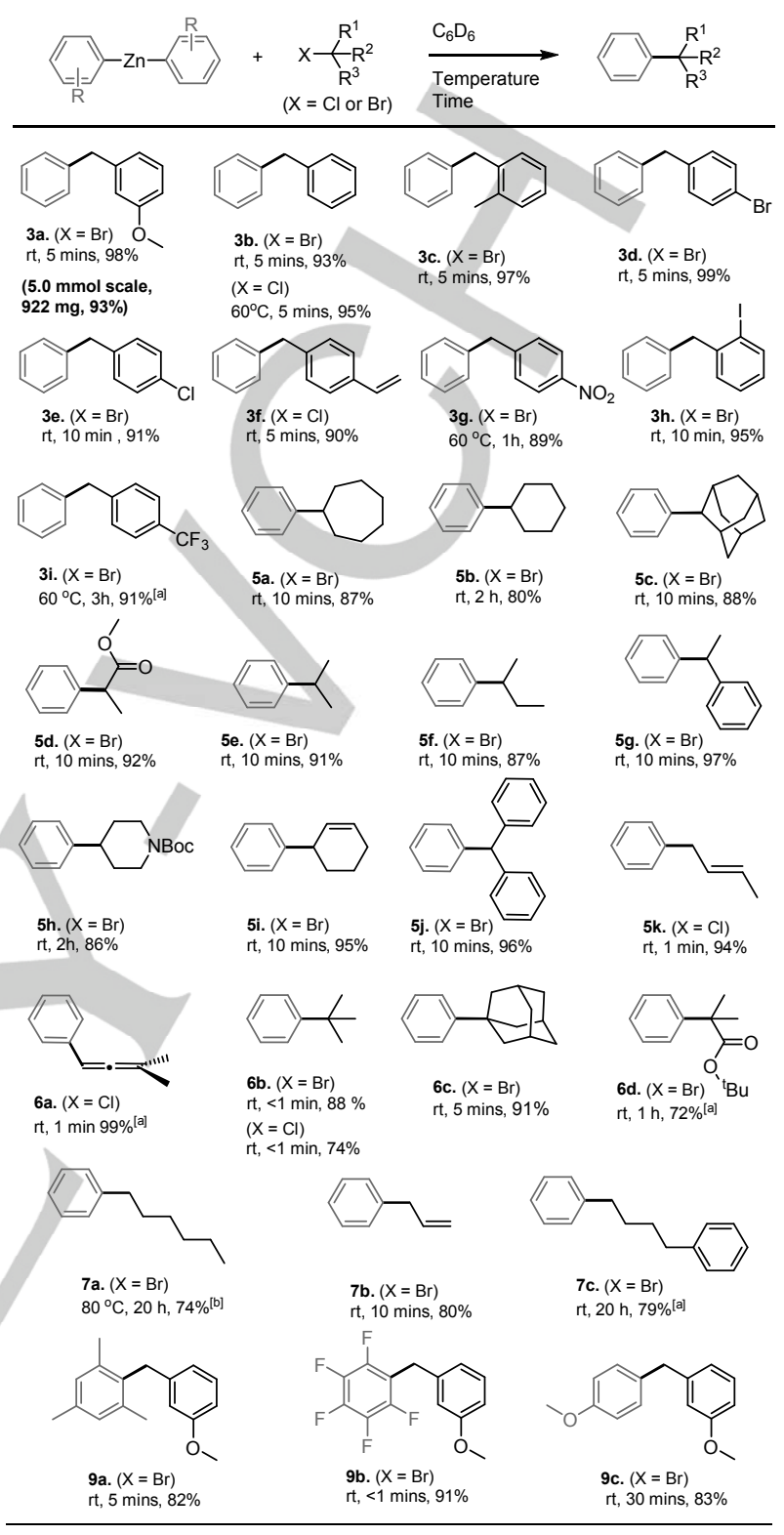

Figure 1. Substrate scope of the $\mathrm{Cs} p^{2}-\mathrm{Csp} p^{3}$ cross-coupling of benzylic, $1^{\circ}, 2^{\circ}$ and $3^{\circ}$ alkyl halides with diarylzinc reagents. Typical reaction conditions: diarylzinc $(0.25 \mathrm{mmol})$; alkyl halide $(0.25 \mathrm{mmol}) ; \mathrm{C}_{6} \mathrm{D}_{6}(1 \mathrm{~mL})$; ambient temperature; $<10$ minutes, isolated yields are reported unless otherwise indicated. ${ }^{\text {[a] }}{ }^{1} \mathrm{H}$ NMR spectroscopy yield. ${ }^{[b]}$ GC-MS yield.

The use of a $2^{\circ}$ allylic electrophile, 3-chloro-but-1-ene, and a tertiary propargylic electrophile, 3-chloro-3-methyl-1-butyne, both led to $S_{N} 2^{\prime}$ products forming $\mathbf{5 k}$ and $\mathbf{6 a}$, respectively. While the latter two classes of electrophile have been previously coupled with arylzinc reagents in THF it is notable that under these etherate-free conditions cross-coupling with $\mathbf{1}$ requires only stoichiometric electrophile and is complete within minutes versus $16 \mathrm{~h}$ using zincates in THF. ${ }^{[25]}$ Tertiary alkyl halides were also readily coupled with 1 at ambient temperature in exceedingly short reaction times $(<$ 5 minutes) to afford compounds $6 \mathbf{b}-\mathbf{d}$ bearing new all-carbon quaternary centers in good to excellent isolated yields (72-91\%). 
These results are remarkable especially when considering that $\mathrm{Csp}{ }^{2}$ $\mathrm{Csp} p^{3}$ cross-coupling incorporating tertiary alkyl halides is extremely challenging even through the employment of state-of-the-art transition metal catalyzed protocols. ${ }^{[34]}$ Finally, we examined the propensity of primary alkyl halide substrates to undergo heterocoupling transformations with 1. While 1-bromohexane could be coupled with 1 to afford $7 \mathrm{a}$ in $74 \%$ yield, this required heating to $80^{\circ} \mathrm{C}$ for $20 \mathrm{~h}$. After $20 \mathrm{~h}$ the complete consumption of 1 bromohexane was observed with the remaining mass balance (26\%) made up by internal isomerization cross-coupled products. ${ }^{[31]}$

We next targeted extending the range of the nucleophilic diarylzinc reagents using 3-methoxybenzyl bromide, $\mathbf{2}$ as the model electrophile. Initial attempts sought to form diarylzinc reagents in THF from Grignard reagents, and in our hands this approach resulted in the isolation of ionic zincates. For example, attempts to form di(p-tolyl)zinc from $p$-TolMgBr (1M in THF) and $\mathrm{ZnBr}_{2}$ in THF led instead to the isolation of zincate species, 8 (identified by X-ray crystallography, Figure 2). In benzene- $d_{6} 8$ exists as a single species displaying one set of THF and $p$-tolyl resonances in the ${ }^{1} \mathrm{H}$ NMR spectrum, comparable to that reported for $\left[\mathrm{Zn}(p \text {-tolyl })_{3}\right]\left[\mathrm{Mg}_{2}(\mu-\right.$ $\left.\mathrm{Cl})_{3}(\mathrm{THF})_{6}\right]^{+}$previously reported by Hevia and co-workers. ${ }^{35]}$ Whilst there is growing literature precedence that zincates are active (and sometimes crucial) ${ }^{[36-38]}$ nucleophiles in transition metal catalyzed cross-coupling operating in more polar solvents (including THF), the combination of 3-methoxybenzyl bromide $3 \mathbf{a}$ ( 0.5 equiv., 1 equiv. per $\mathrm{Zn})$ and 8 in benzene- $d_{6}$ led to no cross-coupling even after extended periods (20h). This outcome is significant given the ubiquity in which diarylzinc reagents are generated from Grignard reagents in-situ in THF.

The lack of cross-coupling using zincate 8 led us to target bonafide examples of etherate-free diarylzinc reagents, a family of compounds that are relatively scarce within the literature. ${ }^{[39-40]}$ Dimesitylzinc has been previously generated etherate-free from mesitylmagnesium bromide and $\mathrm{ZnCl}_{2}$ in $\mathrm{THF}^{[41]}$ Pleasingly, combination of dimesitylzinc with 2 in benzene- $d_{6}$ led to rapid crosscoupling to form 9a in high isolated yield (82\%), with the rate of reaction not appreciably diminished for this highly sterically hindered diarylzinc reagent (Figure 1). Other etherate-free diarylzinc reagents could be generated via lithium / halogen exchange (using $n$-BuLi) and subsequent zincation with $\mathrm{ZnCl}_{2}$ in diethyl ether, with all diethyl ether subsequently removed in-vacuo $\left(5 \times 10^{-2}\right.$ mbar, ambient temperature, $2-5 \mathrm{~h}$ ). Etherate-free diarylzinc reagents, incorporating

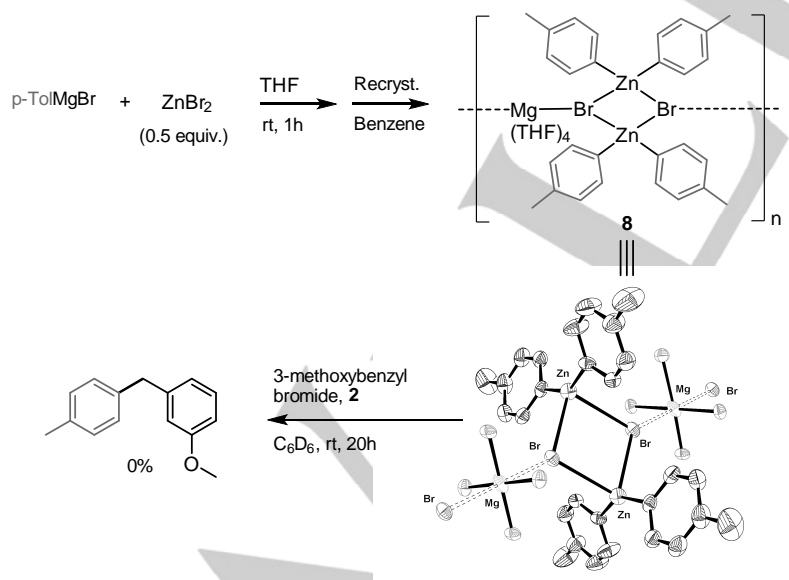

Figure 2. Synthesis of zincate species 8 and reactivity with 2 under the standard cross-coupling conditions. ORTEP representation of part of the extended solid state structure of $\mathbf{8}$, with ellipsoids at $50 \%$ probability. Hydrogen atoms and solvent molecules (benzene) have been omitted for clarity, THF molecules have also been simplified to oxygen for clarity. electron withdrawing and electron donating substituted aromatics also underwent cross-coupling cleanly to afford the desired products $9 \mathrm{~b}$ and $9 \mathrm{c}$ in high isolated yields (91\% and $83 \%$, respectively). In each case the aryl zinc halide by-product precipitated from benzene enabling facile assessment of reaction completion.

In order to further demonstrate the utility of this protocol we synthesized, without the aid of a glovebox, a precursor to the naturally occurring 2,4-bis(4-hydroxybenzyl)phenol, 12 (Figure 3). ${ }^{[42]}$ Compound 12 was recently reported to be an inhibitor of Heat Shock Transcription Factor 1 providing an enhancement to the effectiveness of conventional anticancer agents (e.g., cisplatin and paclitaxel). ${ }^{[43]} \mathrm{Di}(p$-anisole)zinc was generated in-situ via lithium / halogen exchange of 4-bromoanisole with $n$-BuLi in anhydrous diethyl ether followed by zincation with $\mathrm{ZnCl}_{2}$. After filtration and removal of all volatiles in-vacuo $\left(5 \times 10^{-2}\right.$ mbar, ambient temperature, $3 \mathrm{~h}$ ), the resultant white microcrystalline solid was taken up in anhydrous protio-benzene prior to the addition of 2,6di(bromomethyl)anisole, 10 (0.5 equiv.). This resulted in the formation of $\mathbf{1 1}$ as the major product within 30 minutes at ambient temperature.

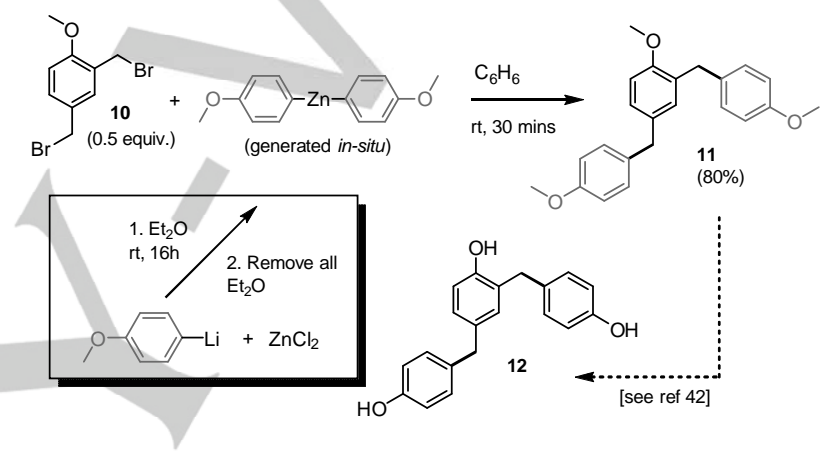

Figure 3. Glovebox-free synthesis of a precursor to the naturally occurring 2,4-bis(4-hydroxybenzyl)phenol.

Regarding the mechanism of this novel cross-coupling protocol a number of preliminary observations are noteworthy. The degree of cross-coupling suppression on addition of ethereal solvents increases as the ether becomes more nucleophilic (with THF having the most pronounced effect of the ethers studied to date). This suggests that coordination of the alkyl halide with the diarylzinc reagent is a key step, with ethers being more nucleophilic towards diarylzinc than alkyl halides disfavoring formation of a $\mathrm{Ph}_{2} \mathrm{Zn}\{\mathrm{X}$ Alkyl $\}_{n}$ type species. This is supported by calculations (at the M06$2 X / 6-311 G+(d, p) / P C M(B e n z e n e)$ level) which indicate that coordination of THF to 1 is energetically $5.3 \mathrm{kcalmol}^{-1}$ more favored than the binding of benzyl bromide to 1 . Qualitative comparison of the relative rates of cross-coupling for various diarylzinc reagents is also informative. The employment of di(pentafluorophenyl)zinc led to complete conversion to the corresponding diarylmethane $\mathbf{9 b}$ within 1 minute at ambient temperature, while in contrast di $(p$-anisole)zinc gave a reduced rate of reaction (30 mins), with diphenylzinc displaying intermediate reactivity ( 5 mins). This observation is consistent with an increase in the relative Lewis acidities of the diarylzinc reagents from $\mathrm{Zn}(p \text {-anisole })_{2}<\mathrm{Zn}(\mathrm{Ph})_{2}<\mathrm{Zn}\left(\mathrm{C}_{6} \mathrm{~F}_{5}\right)_{2}$. This ordering of Lewis acidity was confirmed by the increased magnitude of downfield $\Delta \delta{ }^{31} \mathrm{P}$ on coordination of $\mathrm{Et}_{3} \mathrm{PO}$ to the diarylzinc reagents which also follows the expected order of increasing Lewis acidity $\mathrm{Zn}\left(\mathrm{C}_{6} \mathrm{~F}_{5}\right)_{2}>\mathrm{Zn}(\mathrm{Ph})_{2}>\mathrm{Zn}(p \text {-anisole })_{2 .}{ }^{[31]}$ As previously mentioned the less nucleophilic aryl ethers (relative to aliphatic ethers) do not display any appreciable rate retardation. An increase in Lewis acidity towards zinc can be expected to favour the formation of adducts of the type $(\operatorname{aryl})_{2} Z n\{X-A l k y l\}_{n}$ and is also consistent with the observed coupling suppression using the halide bridged zincate species, $\mathbf{8}$, which is presumably significantly less electrophilic than bona-fide diarylzinc reagents. Attempts to observe any $(\text { aryl })_{2} \mathrm{Zn}\{\mathrm{X}$ Alkyl $\}_{n}$ species in solution at ambient temperature from combination 
of 1 -bromohexane and 1 or $\mathrm{Zn}\left(\mathrm{C}_{6} \mathrm{~F}_{5}\right)_{2}$ by multinuclear NMR spectroscopy and DOSY NMR were however inconclusive. ${ }^{[31]}$

The recent zinc catalyzed borylation of alkyl halides was proposed to be mediated by radical intermediates. ${ }^{[23]}$ This also appears to be the case with this $\mathrm{C} s p^{2}-\mathrm{C} s p^{3}$ cross-coupling protocol as indicated by the formation of the bibenzyl as a minor product (8\%) observed in the formation of $3 \mathbf{i}^{[31]}$ The use of the radical probe 6 bromo-1-hexene in cross-coupling with $\mathbf{1}$ in benzene further supported the intermediacy of radical species in this process with the major product being phenylcyclohexane, $\mathbf{5 b}$ derived from an endoradical cyclisation of a radical intermediate (Figure 4). No linear cross-coupled product or (cyclopentylmethyl)benzene from the exoradical cyclisation were observed. It is however interesting to note that attempted trapping of radical intermediates in the model reaction with 9,10-dihydroanthracene ( 8 equivs) ${ }^{[23]}$ failed and quantitative cross-coupling was observed within 10 minutes at ambient temperature. ${ }^{[31]}$ Radical mediated alkylations using zinc reagents are documented, including examples initiated by the coordination of Lewis bases to $\mathrm{ZnR}_{2}{ }^{[44-46]}$ Thus it is feasible that $\mathrm{R}_{2} \mathrm{Zn}\{\mathrm{X}-\mathrm{Alkyl}\}_{\mathrm{n}}$ intermediates result in a related radical alkylation pathway. Additional mechanistic studies are currently underway to examine this process further.

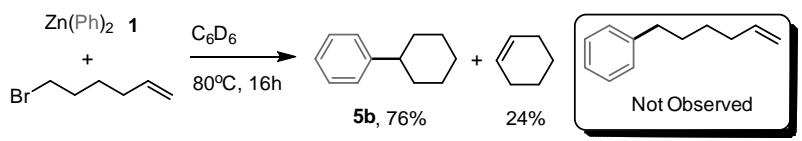

Figure 4. Preliminary mechanistic experiment consistent with radical mediated reactivity.

In summary, from the initial unexpected discovery of crosscoupling between diphenylzinc and 3-methoxybenzyl bromide in benzene- $d_{6}$ we have developed an operationally simple and efficient method for the direct $\mathrm{Csp}^{2}-\mathrm{C} s p^{3}$ cross-coupling of diarylzinc reagents with benzylic, $1^{\circ}, 2^{\circ}$ and $3^{\circ}$ alkyl halides. Reactivity was found to be highly solvent dependent with the presence of even one equivalent of coordinating ethereal solvent being exceedingly detrimental to subsequent reactivity. Preliminary mechanistic studies suggest Lewis acidity at zinc is important, and that the coupling involves radical species. Current work in our laboratory is ongoing with regard to mechanism elucidation as well as extension of substrate scope.

Keywords: Zinc $\cdot$ Cross-Coupling $\cdot \mathrm{Csp}^{2}-\mathrm{C} s p^{3} \cdot$ Diarylzinc $\cdot$ Synthetic methods

[1] A. De Meijere, F. Diederich, Metal-catalysed cross-coupling reactions (Wiley-VCH, 2004).

[2] J. Magano, \& J. R. Dunetz, Chem. Rev. 2011, 106, 2177-2250.

[3] K. C. Nicolaou, P. G. Bulger, D. Sarlah, Angew. Chem. Int. Ed. 2005, $44,4442-4489$

[4] A. Rudolph, M. Lautens, Angew. Chem. Int. Ed. 2009, 48, 2656-2670.

[5] T. Thaler, B. Haag, A. Gavryushin, K. Schober, E. Hartmann, R. M. Gschwind, H. Zipse, P. Mayer, P. Knochel, Nature Chem. 2010, 2, 125-130.

[6] L. Li, C-Y. Wang, R. Huang, M. R. Biscoe, Nature Chem. 2010, 2, 125130.

[7] C. Valente, S. Baglione, D. Candito, C. J. O'Brien, M. G. Organ, Chem. Commun. 2008, 735-737.

[8] G. A. Molander, Editor. (Georg Thieme Verlag KG, 2012).

[9] P. Lundin, G. C. Fu, J. Am. Chem. Soc. 2010, 132, 11027-11029.

[10] H.-Q Do, E. R. R. Chandrashekar, G. C. Fu, J. Am. Chem. Soc. 2013, 135, 16288-16291

[11] Y. Liang, G. C. Fu, J. Am. Chem. Soc. 2014, 136, 5520-5524

[12] S. Biswas, D. J. Weix, J. Am. Chem. Soc. 2013, 135, 16192-16197.
[13] M. Giannerini, M. Fananás-Mastral, B. L. Feringa, Nature Chem. 2013, $5,667-672$.

[14] A. Bonet, M. Odachowski, D. Leonori, S. Essafi, V. K. Aggarwal, Nature Chem. 2014, 6, 584-589.

[15] A. Fürstner, A. Leitner, M. Méndez, H. Krause, J. Am. Chem. Soc. 2002, 124 (46), 13856-13863.

[16] R. Martin, A. Fürstner, Angew. Chem. 2004, 116, 4045 -4047.

[17] A. K. Steib, T. Thaler, K. Komeyama, P. Mayer, P. Knochel, Angew. Chem. Int. Ed. 2011, 50, 3303 -3307.

[18] O. M. Kuzmina,.A. K. Steib, J. T. Markiewicz, D. Flubacher, P. Knochel, Angew. Chem. Int. Ed. 2013, 52, 4945 -4949.

[19] T. Hatakeyama, M. Nakamura, J. Am. Chem. Soc. 2007, 129, 98449845.

[20] C. J. Adams, R. B. Bedford, E. Carter, N. J. Gower, M. F. Haddow, J. N. Harvey, M. Huwe, M. Ángeles Cartes, S. M. Mansell, C. Mendoza, D. M. Murphy, E. C. Neeve, J. Nunn, J. Am. Chem. Soc. 2012, 134, 10333-10336.

[21] X.-F. Wua, H. Neumann, Adv. Syn. Catal. 2012, 354, 3141-3160.

[22] J. Rudolph, C. Bolm, P-O. Norrby, J. Am. Chem. Soc. 2005, 127, 15481552.

[23] S. K. Bose, K. Fucke, L. Liu, P. G. Steel, T. B. Marder, Angew. Chem. Int. Ed. 2014, 53, 1799-1803.

[24] M. Arai, T. Kawasuji, E. Nakamura, Chem. Lett. 1993, 22, 357-360.

[25] T. Furuyama, M. Yonehara, S. Arimoto, M. Kobayashi, Y. Natsumoto, M. Uchiyama, Chem. Eur. J. 2008, 14, 10348 - 10356.

[26] J. J. Dunsford, I. A. Cade, K. L. Fillman, M. L. Neidig, M. J. Ingleson, Organometallics 2014, 33, 370-377.

[27] R. B. Bedford, E. Carter, P. M. Cogswell, N. J. Gower, M. F. Haddow,

J. N. Harvey, D. M. Murphy, E. C. Neeve, J. Nunn, Angew. Chem. Int. Ed. 2013, 52, 1285-1288.

[28] R. B. Bedford, M. A. Hall, G. R. Hodges, M. Huwe, M. C. Wilkinson Chem. Commun. 2009, 6430-6432.

[29] G. A. Olah, Friedel-Crafts chemistry (interscience monographs on organic chemistry) (Wiley-VCH, 1973)

[30] R. B. Bedford, N. J. Gower, M. F. Haddow, J. N. Harvey, J. Nunn, Angew. Chem. Int. Ed. 2012, 51, 5435 -5438.

[31] See supporting information.

[32] I. Thomé, A. Nijs, C. Bolm, Chem. Soc. Rev. 2012, 41, 979-987.

[33] S. Mondal, G. Panda, RSC Adv. 2014, 4, 28317-28358.

[34] S. L. Zultanski, G. C. Fu, J. Am. Chem. Soc. 2013, 135, 624-627.

[35] E. Hevia, J. Z. Chua, P. García-Álvarez, A. R. Kennedy, M. D. McCall, PNAS 2010, 107, 5294-5299

[36] L. Jin, C. Liu, J. Liu, F. Hu, Y. Lan, A. S. Batsanov, J. A. K. Howard, T. B. Marder, A. Lei, J. Am. Chem. Soc. 2009, 131, 16656-16657.

[37] L. C. McCann, M. G. Organ, Angew. Chem. Int. Ed. 2014, 53, 43864389.

[38] L. C. McCann, H. N. Hunter. J. A. C. Clyburne, M. G. Organ, Angew. Chem. Int. Ed. 2012, 51, 7024-7027.

[39] M. H. Chisholm, J. C. Gallucci, H. Yin, H. Zhen, Inorg. Chem. 2005, 44 4777-4785.

[40] S. Brooker, N. Bertel, D. Stalke, M. Noltemeyer, H. W. Roesky, G. M. Sheldrick, F. T. Edelmann, Organometallics 1992, 11, 192-195.

[41] M. Irwin, T. Krämer, J. E. McGrady, J. M. Goicoechea Inorg. Chem. 2011, 50, 5006-5014.

[42] D. Srimani, A. Bej, A. Sarkar, J. Org. Chem. 2010, 75, 4296-4299.

[43] T. Yoon, G-Y. Kang, A.-R. Han, E.-K., Seo, Y.-S. Lee, J. Nat. Prod. 2014, 77, 1123-1129.

[44] E. Hevia, G. W. Honeyman, A. R. Kennedy, R. E. Mulvey, J. Am. Chem. Soc. 2005, 127, $13106-13107$

[45] E. Rijnberg, J. Boersma, J. T. B. H. Jastrzebski, M. T. Lakin, A. L. Spek, G. van Koten, Organometallics 1997, 16, $3158-3164$.

[46] D. R. Armstrong, L. Balloch, J. J. Crawford, B. J. Fleming, L. M. Hogg, A. R. Kennedy, J. Klett, R. E. Mulvey, C. T. O'Hara S. A. Orra, S. A. Robertson, Chem. Commun. 2012, 48, 1541 - 1543. 
Entry for the Table of Contents (Please choose one layout)

\section{COMMUNICATION \\ COMMUNICATION}

Zinc and you'll miss it! Direct $\mathrm{C} s p^{2}-\mathrm{C} s p^{3}$ cross-coupling of diarylzinc reagents with benzylic, $1^{\circ}, 2^{\circ}$ and $3^{\circ}$ alkyl halides proceeds rapidly at ambient temperature in the absence of coordinating ethereal solvents or any added catalyst. This approach to $\mathrm{C} s p^{2}-\mathrm{C} s p^{3}$ bond formation represents an expedient, operationally simple method for the construction of a diverse array of carbon-based structural motifs.

Jay J. Dunsford, Ewan R. Clark \&

Michael J. Ingleson*

Page No. - Page No.

Direct $\mathrm{Csp}^{2}-\mathrm{Csp}{ }^{3}$ cross-coupling of diarylzinc reagents with benzylic, $1^{\circ}$, $2^{\circ}$ and $3^{\circ}$ alkyl halides 